\title{
Health technology assessment-based development of a Spanish breast cancer patient decision aid
}

\author{
Fátima Izquierdo, Javier Gracia, Mercedes Guerra, \\ Juan Antonio Blasco, Elena Andradas \\ Agencia Laín Entralgo
}

Objectives: The aim of this study was to develop a breast cancer Patient Decision Aid (PDA), using a Health Technology Assessment (HTA) process, to assist patients in their choice of therapeutic options, and to promote shared decision making among patients, healthcare professionals, and other interested parties.

Methods: A systematic review (SR) was conducted of existing breast cancer patient Decision Aids encountered in the main scientific journal databases and on institutional Web sites that create PDAs, together with a Qualitative Research (QR) study, using semi-structured interviews and focus group with stakeholders (patients, family members, and health professionals), with the aim of developing a PDA for breast cancer.

Results: The SR shows that PDAs in breast cancer not only increase patient knowledge of the illness, leading to more realistic expectations of treatment outcomes, but also reduce passivity in the decision-making process and facilitate the appropriate choice of treatment options in accordance with patient medical and personal preferences. The analysis of QR shows that both breast cancer patients and healthcare professionals agree that surgery, adjuvant treatments, and breast reconstruction represent the most important decisions to be made. Worry, anxiety, optimism, and trust in healthcare professionals were determined as factors that most affected patients subjective experiences of the illness. This HTA was used as the basis for developing a PDA software program.

Conclusions: The SR and QR used in the development of this PDA for breast cancer allowed patients to access information, gain additional knowledge of their illness, make shared treatment decisions, and gave healthcare professionals a deeper insight into patient experiences of the disease.

Keywords: Health technology assessment, Patient decision aids, Breast cancer, Shared decision making, Qualitative Research

\footnotetext{
The authors thank Ms. Petra Díaz del Campo Fontecha for her participation and collaboration during the qualitative research segment and Ms. María Soriano Cirugeda and Ms. Raquel Luengo González for their methodological contributions and comments, which contributed to the improvement of the PDA. We would also like to thank Mr. Ladislao Bapory for his comments and help with the English version of this study.

Source of Funding: This project was partially financed by the Spanish Quality Plan for the National Health System overseen by the Ministry of Health and
} Social Policy. 
All too often, there is minimal or inappropriate evidence of the benefit/risk of the different cancer treatments involved, with the added uncertainty that outcomes tend to vary from one individual to another (2). Patient subjective perceptions of how they feel, their judgment of how long treatments should last, or their knowledge of the pros and cons of chosen treatments also vary significantly. Approximately, 50 percent of newly diagnosed breast cancer patients feel clinically significant levels of anxiety, distress, or depression. In this context, Breast cancer Patient Decision Aids (PDA) are useful for increasing patient knowledge and confidence in the decision-making process, while serving to reduce decisional conflicts (2).

Given the lack of appropriate aid tools within this area, the Madrid based Lain Entralgo Agency's Health Technology Assessment Unit (UETS) has identified the need to develop a national PDA. In Spain, a generally paternalistic attitude among physicians toward breast cancer patients still exists. However, our objective has been to create a PDA based on both a review of scientific evidence and patient opinions and experience, using a systematic and rigorous HTA process. The systematic approach used has enabled this research group to create a PDA of international relevance, given that it is appropriate for use in all Spanish speaking countries

The objective of this research was to create a tool to facilitate shared patient/physician decision making. The resulting PDA allows patients, through face to face collaboration with healthcare professionals, to adopt a more active role in the choice of treatment options, in accordance with medical and personal preferences.

\section{METHODS}

A systematic review (SR) of existing breast cancer patient PDAs, as well as a series of qualitative research (QR) interviews of patients, family members, and healthcare professionals was conducted to create a specifically designed PDA for breast cancer patients, in accordance with IPDAS (International Patient Decision Aid Standards) methodology (3).

\section{Systematic Review}

The PDAs included in the study, published in both English and Spanish between 1999 and December 2009, were found in MEDLINE, EMBASE, CINAHL, PsycINFO, Cochrane Library, INAHTA, and CRD databases.

Clinical Practice Guidelines (CPG) for breast cancer patients were also reviewed from varying sources, such as the National Guideline Clearinghouse (USA), the Canadian Medical Association, the National Library for Health (UK), the National CPG Program of Spain (GuiaSalud), New Zealand Guidelines Group (NZGG), and the National Health, and Medical Research Council (NHMRC) of Australia.

Health Technology Assessment Agency publications and the Web sites of international institutions working
Table 1. Inclusion and Exclusion Criteria for Breast Cancer PDA Studies

\begin{tabular}{|c|c|c|}
\hline & Inclusion criteria & Exclusion criteria \\
\hline $\begin{array}{l}\text { 1) Types of } \\
\text { studies }\end{array}$ & $\begin{array}{l}\text {-SR of breast cancer } \\
\text { PDAs } \\
\text {-Breast cancer CPGs } \\
\text {-Primary breast cancer } \\
\text { PDA studies }\end{array}$ & $\begin{array}{l}\text {-Narrative reviews } \\
\text {-Single cases/ series of } \\
\text { case studies } \\
\text {-Expert consensus }\end{array}$ \\
\hline $\begin{array}{l}\text { 2) Types of } \\
\text { participants }\end{array}$ & $\begin{array}{l}\text { Studies concerning } \\
\text { women breast cancer } \\
\text { patients who had } \\
\text { taken decisions on } \\
\text { diverse therapeutic } \\
\text { options }\end{array}$ & $\begin{array}{l}\text { Studies concerning } \\
\text { healthcare } \\
\text { professionals who } \\
\text { had taken decisions } \\
\text { on the health of } \\
\text { breast cancer patients }\end{array}$ \\
\hline $\begin{array}{l}\text { 3) Types of } \\
\text { interventions }\end{array}$ & $\begin{array}{l}\text { Studies on } \\
\text { interventions } \\
\text { designed to offer } \\
\text { breast cancer } \\
\text { patients assistance } \\
\text { with deliberate and } \\
\text { specific decision } \\
\text { making regarding } \\
\text { several possible } \\
\text { intervention options } \\
\text { (4) }\end{array}$ & $\begin{array}{l}\text { Studies on } \\
\text { interventions not } \\
\text { oriented toward } \\
\text { specific decision } \\
\text { making: } \\
\text { - Counseling } \\
\text { - Informed consent } \\
\text { - Educational } \\
\text { interventions } \\
\text { - Interventions with } \\
\text { recommended } \\
\text { options rather than } \\
\text { choices based on } \\
\text { personal values }\end{array}$ \\
\hline
\end{tabular}

SR, systematic review; PDA, patient decision aid; CPG, clinical practice guideline.

with PDAs, such as the Ottawa Hospital Research Institute (OHRI), the Foundation for Informed Medical Decision Making (USA), and the "informedhealthchoice" group (Cardiff University) were also reviewed.

The inclusion and exclusion criteria are shown in Table 1. The evidence presented in the selected studies was classified in accordance with SIGN (Scottish Intercollegiate Guidelines Network) (18) recommendations, the Oxman et al. checklist for systematic reviews (15), the Guyatt et al. checklist for clinical trials and observational studies (5), and the QARI (Critical Evaluation Instrument) checklist for qualitative studies (16). CPGs were assessed with the AGREE instrument (Appraisal of Guidelines Research and Evaluation) (21). Finally, the Quality assessment of the PDAs found was analyzed in accordance with IPDAS quality criteria (3).

\section{Qualitative Research}

Semi-structured interviews and focus group discussion methods were used to assess the psychosocial needs of female breast cancer patients. Information on patients requests and their personal experiences of the illness was gathered, while the specific needs arising in the therapeutic options decisionmaking process were identified through group discussions.

Semi-structured interviews with healthcare professionals, breast cancer patients, and family members were 
Table 2. Script Used for Semi-structured Interviews and Focus Group With Health Professionals, Patients, and Family Members

\begin{tabular}{ll}
\hline Topics & Content to include \\
\hline Decision & - Most important decisions a person with \\
& breast cancer makes \\
& - Difficulties in cancer-related decision making \\
& - Aids and barriers to making the most \\
appropriate decision
\end{tabular}

conducted and audio recorded by a UETS sociologist and a psycho-oncologist, in accordance with the indications stated in the Jacobsen and O'Connor manual (6). The focus group consisted of breast cancer patients and discussion sessions were synchronized in time with the interviews. The discussion groups were open and provided with a moderator and observer. To structure the total time available, a script to elicit responses to relevant topics was written using relevant aspects from the systematic review. The content of the script is shown in Table 2.

Patients and professionals were selected for interview using similar sampling criteria to the Gorden's four questions-criterions for the selection of contexts and cases (22). Three target-groups were established: healthcare professionals from Spanish hospitals (gynecologist, oncologist, oncology radiotherapy nurse, oncologist surgeon, plastic surgeon, and psycho-oncologist), patients (women with breast cancer, 20 to 85 years old, undergoing any type of treatment and at any stage of the disease), and patient family members. Recruitment was made possible thanks to the personal and social networks of the researchers not involved in the project, including patient organizations. Snowball sampling strategy was used (17) and patient interviews were planned in accordance with the typology shown in Table 3. Criteria identical to that used during the interview stage was applied to define the profiles of the women who participated in the focus group.
Table 3. Breast Cancer Patient Profile Items

Age (young, middle aged, old)

Marital status (single, married, separated/divorced, widow)

Level of education (basic, some university, university degree)

Degree of health/disease stage (beginning, treatment stage, disease-free stage)

Treatments-Relapses (mastectomy, preservation surgery, chemotherapy, radiotherapy, hormonal therapies)

Location (corresponding district hospital; Spanish Healthcare System)

Before interviews and focus group discussions, informed consent was requested to ensure that the information collected could be used for research purposes. A transcription of the interviews and focus group discussions was analyzed, inserting the most representative verbatim within a basic categorization (Topics, Table 2). Simultaneously, the qualitative assessment of the data collected was processed with qualitative analysis software (NVIVO8).

\section{Design of the PDA}

A Patient Decision Aid Tool for women breast cancer patients was created through an HTA process, involving the SR and $\mathrm{QR}$ described. The information gathered was included in the content of the PDA, together with the results from $\mathrm{QR}$ on the needs expressed by members of the focus group during the therapeutic option decision-making process. The most appropriate PDA format was determined, in accordance with IPDAS (3) and the Ottawa Decision Support Framework (13) criteria.

\section{RESULTS}

\section{Systematic Review}

Subsequent to the elimination of duplicated studies, a total of 512 were identified as relevant for our purposes, from a total of 564. A further reading of the abstracts, resulted in the selection of 263 studies, from which 10 were finally chosen for this work. Of this final total, two were SRs, two were CPGs, and six were primary studies (three RCTs, one quasiexperimental study, one descriptive study, and one qualitative study) $(1 ; 7-9 ; 11 ; 14 ; 19 ; 20 ; 23 ; 24)$. The results gathered, in accordance with IPDAS group evaluation criteria $(3 ; 11)$, are shown in Table 4.

\section{Qualitative Research}

The healthcare professionals interviewed included: one gynecologist, one oncologist, one oncology radiotherapy nurse, one oncologist surgeon, two plastic surgeons, and one psycho-oncologist. Two patients and two family members were also interviewed individually. The focus group included six patients. The interviews and focus group were conducted at UETS facilities, with the exception of five interviews 
Izquierdo et al.

Table 4. Results of the SR of Breast Cancer PDAs

\begin{tabular}{|c|c|}
\hline $\begin{array}{l}\text { Attributes of } \\
\text { the } \\
\text { decision }\end{array}$ & $\begin{array}{l}\text {-Knowledge score: PDAs improved breast cancer } \\
\text { patient understanding of the disease when } \\
\text { compared with standard interventions } \\
\text { (consultation rooms) }(14 ; 15 ; 18 ; 21 ; 22) \\
\text {-Accurate risk perceptions: PDAs containing } \\
\text { detailed probabilities of intervention outcomes } \\
\text { generated a significantly larger proportion of } \\
\text { women with breast cancer with real perceptions } \\
\text { of risk when compared with those who did not } \\
\text { receive this information (1.6 RR; } 95 \% \text { CI: } 1.4 \\
\text { to } 1.9) \text {. There was a higher effect of accurate } \\
\text { risk perception when probability was measured } \\
\text { quantitatively and described in numbers (versus } \\
\text { probability measured qualitatively and } \\
\text { described in words). PDAs with a decisional } \\
\text { balance table also showed an increase in the } \\
\text { individual perception of risk regarding the } \\
\text { recurrence of breast cancer with or without } \\
\text { chemotherapy (15;21;22). } \\
\text {-Value congruence with chosen option: Women } \\
\text { with breast cancer who used a tool with explicit } \\
\text { clarification of values when deciding on } \\
\text { hormonal therapy after menopause versus a tool } \\
\text { without this clarification, showed a greater } \\
\text { congruency between patient values and the } \\
\text { selected option ( } 40 \% \text { vs. } 0 \% \text {, p = .06) (15). }\end{array}$ \\
\hline $\begin{array}{l}\text { attributes of } \\
\text { the } \\
\text { decision } \\
\text { process }\end{array}$ & $\begin{array}{l}\text {-The use of PDAs showed less conflict between } \\
\text { decision making and standard interventions } \\
\text { when it came to feeling uninformed ( }-8.3 \mathrm{MD} \text {; } \\
\text { 95\% CI: }-11.9 \text { to }-4.8 \text { ) and ambivalent about } \\
\text { personal values ( }-6.1 \mathrm{MD} \text {; } 95 \% \mathrm{CI}:-8.6 \text { to } \\
\text {-3.6) (15). Both criteria were evaluated with } \\
\text { subscales of the Decisional Conflict Scale } \\
\text { (10;24). } \\
\text {-With PDAs the number of women taking a } \\
\text { passive role in decision making and those } \\
\text { remaining indecisive after the intervention } \\
\text { decreased. Invasive surgical treatments also } \\
\text { decreased in favor of conservative options } \\
\text { (PDA vs. standard attention), as did the use of } \\
\text { hormones during menopause when using } \\
\text { detailed PDAs. However, PDAs did not show } \\
\text { significantly improvement on standard } \\
\text { interventions when it came to satisfaction with } \\
\text { decision making, anxiety, and health outcomes } \\
\text { (generic and specific to the pathology) (15). }\end{array}$ \\
\hline
\end{tabular}

PDAs, patient decision aids; RR, relative risk; CI, confidence interval; $\mathrm{P}$, $p$-value; MD, mean deviation.

with healthcare professionals, carried out in their respective hospitals. Results of the QR were grouped into the following subject sections (See Method Topics, Table 2).

Decisions. Clinicians, patients, and family members consider surgery, adjuvant treatments, and breast reconstruction as the most important decisions to be made. Patients and family members judged the main difficulties in decision making to be: the absence of a trusted professional from whom to receive information, a lack of support from family members, myths regarding treatment side effects, and little assistance in decision making. Healthcare professionals believe that difficulties arise due to a lack of decision-making skills, little trust in the professional, age ("the younger the patient the more decisional conflict"), uncertainty regarding the most important aspects, changes in body image, and social pressure ("especially from close family"). Both professionals and family members considered the following aspects as helpful for decision making: patient awareness of their own involvement in the decision-making process, support (from psychologists, physicians, spouses and patient associations), reliable general information, and probability projections associated with each therapeutic option.

Perceptions: Subjective Experience and Expectations. Healthcare professionals believe that patients have an inherent desire to trust physicians, as a means to overcoming "the fears" surrounding their illness. Patients themselves expressed both negative (feelings of imminent death, loneliness, worry, and anxiety) and positive emotions (selfencouragement, confidence in their chosen choice of action, optimism).

Other People Involved. Patients and healthcare professionals taking part in our qualitative research stated that although spouses should play a supportive role in the decisionmaking process, any final decision should be made by patients themselves. Close family members believe that they and the family doctor should be involved in the process.

Decision-Making Behavior: Decisional Conflict. In an attempt to reduce decisional conflict, patients show a tendency to seek a second medical opinion and alternative therapies. Clinicians believe that patients should practice relaxation techniques or participate in discussion groups to gain support from other patients facing the same illness.

Ideal PDA Format and Contents. Patients consider that PDAs in hard copy format provide immediate availability, while multimedia formats, such as a computer application were considered as ideal and effective at offering detailed information on treatment phases in interactive modules. Information on body image and chemotherapy side effects was also important to patients. Family members specified information on benefits/risks expressed in terms of probability as important and clinicians highlighted the need for a simple, picture-based, and interactive format.

\section{Patient Decision Aids for Breast Cancer: The Tool}

The PDA includes clinical information about invasive and noninvasive breast cancer treatment. It is not aimed at patients with lobular carcinoma in situ, nor inflammatory breast cancer. Results of the QR led to the selection of software with support material on paper as the most appropriate format, allowing the patient immediate access to the contents. The software was designed and developed by a UETS psychooncologist and a multimedia content specialist, under the 
technical direction of the UETS. The PDA offers an interrelated treatment sequence that leads to a particular situation created specifically for the user. It includes visual aids that explain the probability of benefits/risks, information regarding body image, experiences of other people in similar situations, decisional balance sheets with which to reflect on the pros and cons of each option and, statistical and audio-animated graphics.

The PDA tool is available on the Spanish Network of HTA Agencies website (http://aunets.isciii.es/web/ guest/acceso_apoyo_metodo).

\section{DISCUSSION}

In contrast to the shared decision-making approach taken in English speaking countries $(2 ; 12)$, doctor-patient relationships in this country have been traditionally centered on a more paternalistic approach. However, as is evident from this PDA, this new paradigm is slowly becoming accepted within our healthcare system

The objective of this study was to describe how HTA processes, involving a Systematic Review of evidence and Qualitative Research study, have been used to develop a PDA for female breast cancer patients in Spain. After an assessment of the different "technologies" used in breast cancer treatments, our findings were applied to the development of this tool; the first of its kind in Spanish National Healthcare System within the aforementioned clinical context and an instrument through which Spanish speaking patients and healthcare professionals may manage the uncertainty involved in treatment choices. This tool serves as an aid to gaining a greater understanding of the disease and a deeper awareness of other patient experiences. Moreover, the fact that the systematic approach to obtaining patient preferences and values was effective and the fact that the tool may be used in other Spanish speaking countries endow this PDA with a truly international relevance. Its design has been focused on providing a response to patient needs identified through the HTA process. The methodology used was effective in capturing many spontaneous thoughts, given that patients could freely express their ideas in an encouraging atmosphere of easy going group discussion, based on the principles of sociological pairing (22). For this reason, our sampling has tried to represent all of the psychosocial profiles necessary. With the interviews of both patients and professionals, we have included a dual view of breast cancer; from those who treat it and those who suffer from the disease.

The results would have been even more detailed if we had been able to work with a larger number of patients recruited from different geographical locations. This was not possible due to limited time and resources. Regardless, the qualitative research has obtained answers to all of the questions posed in the script developed from the previous systematic review. The tool is based mainly on experience of the disease and not on organizational differences in the area of assistance.
A validation process of the PDA involving patient participation has yet to be performed, so expectations may not have been incorporated sufficiently. However, a pilot phase with this involvement is planned before the implementation phase to ensure that any pertinent modifications may be incorporated.

The tool's content assists healthcare professionals and patients in the understanding of how diagnosis, clinical history, and personal values and preferences affect decision making regarding treatment options. The tool will also be of great utility value for family members, carers or any other party with an interest in breast cancer.

The emotional impact of a breast cancer diagnosis in combination with the large quantity of contrasting information can be overwhelming for patients, making this PDA essential. With regard to the psychological aspects of the disease, there is no "one size fits all" strategy for patients when it comes to facing cancer. For this reason, personal values and preferences are explored within the tool. The PDA contains decisional balance instruments to assist patients in their choice of treatment options, in accordance with individual preferences.

This tool disregards therapeutic options that present little or insufficient evidence and focuses on the most widely used treatments for which robust published evidence can be found in the main databases. Treatments not endorsed by evidence could confuse patients in the decision-making process.

In conclusion, the present PDA for breast cancer, developed within the framework established by the HTA Agencies, has been created following a systematic and rigorous HTA process. It has succeeded in improving the quality of decisions for specific situations and has encouraged a shared decision-making approach in which both patients and healthcare professionals take on a participative role. This work supports and facilitates objective patient involvement within the HTA process; a need that has already been recognized at an international level by the network of agencies. In addition to incorporating quantitative evidence, it incorporates evidence eliciting patient perspectives obtained through social science research, including primary qualitative research conducted by our team at the UETS (4).

\section{CONTACT INFORMATION}

Fatima Izquierdo, Masters in Psycho-Oncology (fatima.izquierdo@uets.info), Researcher, Javier Gracia, MD, MPH (javier.gracia@salud.madrid.org), Researcher, Mercedes Guerra (mercedes.guerra@uets.info), Academic Librarian, Documentalist; Juan Antonio Blasco, MD, MPH, MHTA (juan.blascoa@salud.madrid.org), Health Technology Assessment Unit (UETS) Director, Elena Andradas, MD, MPH, MHTA, (elena.andradas@salud. madrid.org), Agencia Lain Entralgo, Unidad de Evaluación de Tecnologías Sanitarias, C/Gran Via 27, Madrid 28013, Spain 
Izquierdo et al.

\section{CONFLICT OF INTEREST}

All authors report they have no potential conflicts of interest.

\section{REFERENCES}

1. Early and locally advanced breast cancer: Diagnosis and treatment. NICE. National Collaborating Centre for Cancer; 2009.

2. Edwards A, Elwyn G. Shared decision-making in health care. Achieving evidence based patient choice. 2nd ed. New York, NY: Oxford University Press; 2009.

3. Elwyn G, O'Connor A, Stacey E, et al. Developing a quality criteria framework for patient decision aids: Online international Delphi consensus process. BMJ. 2006;333:417.

4. Facey K, Boivin A, Gracia J, et al. Patients' perspectives in health technology assessment: A route to robust evidence and fair deliberation. Int J Technol Assess Health Care. 2010;26:334-340.

5. Guyatt GH, Sackett DL, Cook DJ. Users' guides to the medical literature. II. How to use an article about therapy or prevention. A. Are the results of the study valid? Evidence-Based Medicine Working Group. JAMA. 1993;270:2598-2601.

6. Jacobsen MJ, O'Connor AM. Population needs assessment. A workbook for assessing patients' and practitioners' decision making needs. Canada: University of Ottawa; 2006.

7. Lacey MD. The experience of using Decisional Support Aids by patients with breast cancer. Oncol Nurs Forum. 2002;29:14911497.

8. Molenaar S, Sprangers MA, Rutgers EJ et al. Decision support for patients with early-stage breast cancer: Effects of an interactive breast cancer CDROM on treatment decision, satisfaction, and quality of life. J. Clin. Oncol. 2001;19:1676-1687.

9. Morris D, Drake E, Saarimaki A, Bennett C, O'Connor A. Can people find patient decision aids on the Internet? Patient Educ Couns. 2008;73:557-560.

10. O'Connor AM. Validation of a decisional conflict scale. Med Decis Making. 1995;15:25-30.

11. O'Connor AM, Bennett CL, Stacey D, et al. Ayudas para personas que deben decidir sobre tratamientos o sobre la participación en pruebas de detección (Revision Cochrane traducida). Biblioteca Cochrane Plus; 2009 Número 3. Oxford: Update Software Ltd. (Traducida de The Cochrane Library, 2009 Issue 3 Art no. CD001431. Chichester, UK: John Wiley \& Sons, Ltd.
12. O'Connor AM, Drake ER, Fiset V, Graham ID, Laupacis A, Tugwell P. The Ottawa patient decision aids. Eff Clin Pract. 1999;2:163-170.

13. O'Connor AM, Jacobsen MJ. Workbook on developing and evaluating patient decision aids. Canada: Ottawa Health Research Institute; 2003. www.ohri.ca/decisionaid (accessed May 10, 2009).

14. OncoGuía de mama. Cataluña, España: Agencia de Evaluación de Tecnología e Investigaciones Médicas de Cataluña (AATRM); 2008.

15. Oxman AD, Cook DJ, Guyatt GH. User's guides to the medical literature. VI. How to use an overview. JAMA. 1994;272:13671371.

16. Pearson A. Balancing the evidence: Incorporating the synthesis of qualitative data into systematic reviews. JBI Rep. 2004;2:4564.

17. Salganik MJ, Heckathorn DD. Sampling and estimation in hidden populations using respondent-driven sampling. Sociol Methodol. 2004;34:193-239.

18. Sing.ac.uk [Internet]. Edinburgh, UK: Scottish Intercollegiate Guidelines Network (SIGN). http://www.sign.ac.uk. (accessed March 25, 2009).

19. Stacey D. Decision making in oncology: A review of patient decision aids to support patient participation. CA Cancer J Clin. 2008;58:293-304.

20. Street RL Jr, Voigt B, Geyer C Jr, Manning T, Swanson GP. Increasing patient involvement in choosing treatment for early breast cancer. Cancer. 1995:76:2275-2285.

21. The AGREE Collaboration. Appraisal of Guidelines for Research \& Evaluation (AGREE) Instrument. London, UK: 2001. www.agreecollaboration.org (accessed March 30, 2009).

22. Valles MS. Entrevistas cualitativas. Colección Cuadernos Metodológicos, NÚM. 32. Madrid: Centro de Investigaciones Sociológicas; 2009.

23. Whelan T, Sawka C, Levine M, et al. Helping patients make informed choices: A randomized trial of a decision aid for adjuvant chemotherapy in lymph node-negative breast cancer. J Natl Cancer Inst. 2003;95:581-587.

24. Whelan T, Levine M, Willan A, et al. Effect of a decision aid on knowledge and treatment decision making for breast cancer surgery. A randomized trial. JAMA. 2004;292:435441. 